\title{
Anhydrite/aerogel composites for thermal insulation
}

\author{
D. Sanz-Pont • D. Sanz-Arauz • \\ C. Bedoya-Frutos $\cdot$ R. J. Flatt $\cdot$ S. López-Andrés
}

Received: 8 August 2015/ Accepted: 13 November 2015/Published online: 19 November 2015

(C) RILEM 2015

\begin{abstract}
High performance thermal insulating composite materials can be produced with mineral binders and hydrophobic aerogel particles through a hydrophilization process for the latter with surfactants. The present study is focused on the development of aerogel/calcium sulfate composites by the hydrophilization of hydrophobic silica aerogel particles through a polymer-based surfactant. Its effects on the microstructure and hydration degree are examined as well as their relation to the resulting mechanical and physical properties. Results show that composites with an around $60 \%$ of aerogel by volume can achieve a thermal conductivity $<30 \mathrm{~mW} / \mathrm{m} \times \mathrm{K}$. Interestingly, a surfactant addition of $0.1 \%$ by wt $\%$ of the water in the mixtures provides better material properties compared to a surfactant wt $\%$ addition of $5 \%$. However, it has been found around $40 \%$
\end{abstract}

D. Sanz-Pont $(\varangle) \cdot$ D. Sanz-Arauz $\cdot$ C. Bedoya-Frutos

Department of Construction and Architectural

Technology, Polytechnic University of Madrid, Madrid,

Spain

e-mail: daniel.sanz@ethz.ch

D. Sanz-Pont · R. J. Flatt

Department of Civil, Environmental and Geomatic Engineering, Institute for Building Materials, ETH

Zürich, Zurich, Switzerland

S. López-Andrés

Department of Crystallography and Mineralogy,

Complutense University of Madrid, Madrid, Spain entrained air, affecting the material properties by reducing the binder and aerogel volume fractions within the composites. Moreover, gypsum crystallization starts to be inhibited at aerogel volume fractions $>35 \%$. Towards material optimization, a model for the calculation of thermal conductivity of composites and an equation for the compressive strength are proposed.

Keywords Aerogel · Surfactant $\cdot$ Anhydrite Composite $\cdot$ SEM $\cdot$ Thermal insulation

\section{Introduction}

The high energy consumption of old buildings is often related to a lack of thermal insulation of the building enclosure [60, 65]. For masonry based buildings, energy saving targets can be met with thermal insulating panels with a suitable hygrothermal behavior [38]. However, such constructive systems require flat surfaces, panel adjustments, gluing and so forth. In contrast, mortars with high thermal insulating properties, besides not presenting the paneling systems disadvantages, can fill gaps and provide a continuous thermal insulating layer avoiding thermal bridges. Their thermal conductivities are however not as low. Nevertheless, enhancements of the thermal insulating properties of mortars can be achieved by using aerogel particles as lightweight thermal insulating aggregates, 
taking advantage of the very low thermal conductivity generated by their nanoporous structure $[8,14,35]$.

There has been a rising interest in aerogels for building applications in the last years, mainly for building insulation $[4,7,27,30,37,39,50,55,66,76]$. Aerogel granules have become more popular than monolithic aerogels due to lower production costs. Lately, a rising use of aerogel granules has been reported as thermal insulating aggregates in composite materials, based on mineral binders $[10,18,24,25,36$, $45,58,64]$. The resulting composites can be used in buildings as renderings or as thermal insulating layers; however, these composite materials typically present low mechanical strength, especially if the target is to achieve high insulating values, as can be observed from [3], with a compressive strength around $0.08 \mathrm{MPa}$ and a thermal conductivity of $34 \mathrm{~mW} / \mathrm{m}$ $\times \mathrm{K}$. Because of this behavior, external rendering applications of these products typically require additional mesh reinforcement and an external protective layer. However, it would be of great interest to be able to reduce or eliminate the need of a mesh reinforcement, by reaching a compressive strength $>0.40 \mathrm{MPa}$, so it can comply with the first category (CS I) of the European Standard 998-1, regarding thermally insulating mortars for exterior applications.

Hydrophobic aerogels are mostly used in building applications. This type of aerogels have undergone a surface modification, which provides the hydrophobic character [32, 41, 43, 54, 61, 63, 68, 69, 72, 74]. In particular, their contact angle with water droplet depends on the silylating agent (non-polar groups) $[43,54,61,69]$. The data regarding water absorption of such aerogels shows that the untreated aerogels (hydrophilic) absorb water by 4-5 times their own weight, while silylated aerogels (hydrophobic), absorb less than $2 \%$ water with respect to their own weight [68]. Nevertheless, the high hydrophobicity of aerogels poses a processing problem when mixed with water based mineral binders. This can be overcome by hydrophilizing the aerogels with surfactants or by adding wetting additives to form a hydrophilic coating around the hydrophobic core of the aerogel particles [18].

Surfactants are amphiphilic compounds that comprise a hydrophilic head and a hydrophobic tail. They are mostly used in the manufacture of detergents, soaps and many other personal care products. In building applications, surfactants have been used recently to form mineral slurries with hydrophobic aerogel particles [10,
$18,36]$, besides other uses, like air-entraining agent to produce freeze-thaw resistant concrete, but also foamed concrete [19, 46, 49, 70, 73]. However, their use in cement-free based composites has received comparatively little attention. One of the objectives of this paper is to remedy this situation because of the promising perspectives offered by such systems as high performance insulating renders. In particular, we examine how the binder matrix hydration and microstructure is affected by the presence of polymeric surfactants and a high concentration of hydrophobic aerogel particles. This sets the basis for a rational discussion of the development of physical and mechanical properties in these novel mineral based composites.

Besides a good thermal insulation, the rehabilitation of old buildings based in historic masonry requires a material compatibility between the repair mortars and the pre-existent main façade material [34], which is why binders compatible with historic mortars should be preferred. From this perspective, it is worth noting that although hemihydrate has been broadly used for developing building composites [13, 17, 22, 26, 31, 42, 48, 67, 75], only anhydrite based binders are considered as repair mortars for exterior applications by RILEM TC203RH [34]. Although allegedly not water resistant, anhydrite based mortars have been successfully used for exterior renderings [2, $40,52,56,57]$ and joints in exterior walls of historic buildings [44]. They appear to present better water resistance and mechanical properties than corresponding binders prepared with hemihydrate, probably because they can be prepared with lower water/binder ratios, producing lower porosities and higher densities in the hardened material. Thus, gypsum based on high anhydrite content and low water/binder ratios can be considered for exterior applications.

The main aim of the present paper is therefore to study the preparation and material properties of thermally insulating renders based on anhydrite binder and aerogel particles. More specifically, we develop our approach by studying the resulting density of the binder matrix and volume content of the components within the composites providing key information about this type of mixtures not reported in other studies before. For this, we first compatibilize the hydrophobic silica aerogel particles with the selected water-based mineral binders by a hydrophilization process through a polyethylene-glycol - polypropylene-glycol - polyethylene-glycol block copolymer 
(PEG-PPG-PEG) based surfactant, then, we study the effect of the surface modification of aerogels by measuring the water absorption capacity during the preparation of the samples, and finally, the resulting microstructure of the composites, the binder hydration, as well as the mechanical, thermal and physical properties. The surfactant used is specifically nonionic, to avoid possible ionic interactions with the mineral binder.

\section{Experimental}

\subsection{Materials}

The composites were produced through the mixture of the following materials, in different ratios:

(1) Anhydrite II (artificial) from CTH Navarra, for the main mineral binder [6], obtained by calcination of natural gypsum between 300 and $700{ }^{\circ} \mathrm{C}$ (particles: $>0.8 \mathrm{~mm}-2 \%,>0.2 \mathrm{~mm}-$ $30 \%$ ). Classified Type A (according to European Standard [21]).

(2) Hydrophobic silica aerogel granules (0.01-1.2 $\mathrm{mm})$ from Cabot, as insulating aggregates [12]. Thermal conductivity $(k)$ of $0.013 \mathrm{~W} / \mathrm{m} \times \mathrm{K}$ at $21{ }^{\circ} \mathrm{C}$, porosity $>90 \%$, particle density $\left(120-180 \mathrm{~kg} / \mathrm{m}^{3}\right)$, oil absorption capacity (5.4-6.5 g/aerogel g).

(3) Non-ionic liquid surfactant (PEG-PPG-PEG) from BASF [53], for the hydrophilization of the aerogel particles. Molar mass of $3650 \mathrm{~g} / \mathrm{mol}$, density of $1.03 \mathrm{~g} / \mathrm{cm}^{3}$, surface tension of $35 \mathrm{mN} / \mathrm{m}$.

(4) Distilled water at $2{ }^{\circ} \mathrm{C}$, for the formation of the gypsum composites slurries.

Table 1 shows the real density of the base materials measured by helium pycnometer and the particle density of the aerogel particles as reported earlier [47].

Table 1 Real density of the base materials

\begin{tabular}{llll}
\hline & $\begin{array}{l}\text { Mineral } \\
\text { binder }\end{array}$ & $\begin{array}{l}\text { Aerogel } \\
\text { particles }\end{array}$ & Surfactant \\
\hline Real density $\left(\mathrm{g} \mathrm{cm}^{-3}\right)$ & 2.732 & 1.845 & $1.03^{*}$ \\
Particle density $\left(\mathrm{g} \mathrm{cm}^{-3}\right)$ & - & $0.155^{* *}$ & - \\
Calculated porosity $(\%)$ & - & 91.6 & - \\
\hline
\end{tabular}

* From technical datasheet, ** [45]

\subsection{Mixtures}

\subsubsection{Surfactant treatment}

In order to reduce the hydrophobic forces of the hydrophobic aerogels, and compatibilize them with water, two different surfactant dosages $(0.1$ and $5 \%$ weight of the solution) were tested within the composite mixtures, measuring the water absorption capabilities of the aerogels after the re-treatment for each case.

\subsubsection{Sample preparation}

The composition of all samples is described in Table 2. The series are divided in two families; A and $\mathrm{B}$. The main difference between both is related to the surfactant amount. The A and B mixtures contain a constant addition of 0.1 and $5.0 \%$ of surfactant respectively in relation to water. The $5 \%$ stands for the concentration typically used to stabilize air bubbles in foamed concrete [70]. The $0.1 \%$ was the lowest concentration we found to be able to stabilize aerogel particles in all the aerogel concentrations, of the A series. Also, each family is further divided into series with different additions of aerogel particles by wt $\%$ of the mineral binder $(0,10,20,30$ and $100 \%)$.

Samples were prepared following the manual procedure described in the European Standard [21] using a rubber spatula $(5.1 \times 7.9 \mathrm{~cm}$, total length $24.2 \mathrm{~cm}$ ), with minor changes. First, the addition of the surfactant to the distilled water; second, the addition of the anhydrite followed by a first $30 \mathrm{~s}$ manual stir; and third, the addition of the aerogel granules followed by another $30 \mathrm{~s}$ manual stir, both describing 30 movements (one per second) in form of number eight. This "gently" manual stirring procedure prevents the aerogel particles from crushing, as could be expected by using a more intense or mechanical mixing process. In addition, this modified procedure allows the anhydrite to hydrate partially before adding the aerogel granules and was found to lead to a better dispersion.

The final slurries are poured into standard molds ( $4 \times 4 \times 16 \mathrm{~cm}, 3$ specimens in two groups), and two $11 \times 5 \times 2 \mathrm{~cm}$ specimens for the thermal conductivity test, for each mixture series. Table 2 also shows the water/binder ratios used in the preparation of the specimens, all having the same flowability $(160 \mathrm{~mm})$ 
Table 2 Sample composition

The components are additions to the mineral binder (wt\% of the mineral binder)

\begin{tabular}{llll}
\hline Name of the series & $\begin{array}{l}\text { Water/binder } \\
\text { (Ratio) }\end{array}$ & $\begin{array}{l}\text { Surfactant } \\
(\% \text { of binder wt. })\end{array}$ & $\begin{array}{l}\text { Aerogel addition } \\
\text { (\% of binder wt. })\end{array}$ \\
\hline Reference gypsum & 0.45 & - & - \\
$\mathrm{A}(0)$ & 0.45 & 0.04 & - \\
$\mathrm{A}(10)$ & 0.69 & 0.07 & 10 \\
$\mathrm{~A}(20)$ & 0.98 & 0.10 & 20 \\
$\mathrm{~A}(30)$ & 1.27 & 0.13 & 30 \\
$\mathrm{~A}(100)$ & 3.60 & 0.36 & 100 \\
$\mathrm{~B}(0)$ & 0.45 & 2 & - \\
$\mathrm{B}(10)$ & 0.81 & 4 & 10 \\
$\mathrm{~B}(20)$ & 1.20 & 6 & 20 \\
$\mathrm{~B}(30)$ & 1.59 & 8 & 30 \\
$\mathrm{~B}(100)$ & 4.62 & 22 & 100 \\
\hline
\end{tabular}

according to the European Standard [21] (this also led to measure the water absorption capacity of the retreated aerogels during sample preparation). Laboratory conditions: $21{ }^{\circ} \mathrm{C}$ and $50 \% \mathrm{RH}$.

\subsection{Sample testing methods}

\subsubsection{Physical and mechanical properties}

Physical and mechanical tests were made by the procedure described in the European Standard [21], cured at $21{ }^{\circ} \mathrm{C}$ and $50 \%$ RH for 7 days and then dried up to constant weight at $45{ }^{\circ} \mathrm{C}$. The apparent porosity $\%$ (water accessible porosity), was determined by the Archimedes method, by the immersion of the samples in water at RT for $24 \mathrm{~h}$. The water absorption tests were made by the procedure described in the European Standard [20]. For thermal conductivity, a FP2C Neotim (ASTM 5930-97 standard), with the "Hot wire" method described in RILEM [1], with a measurement range between 0.02 and $5 \mathrm{~W} / \mathrm{m} \cdot \mathrm{K}$. In this test, specific probe is sandwiched between two plates of the material to be measured, so that the thermal response is an average between the properties of both plates. For real density of the base materials, a Helium Pycnometer Micrometrics AccuPyc II 1340.

\subsubsection{Mineralogical and microstructure characterization}

For X-Ray diffraction analysis, a Bruker D8 Advance diffractometer, working in Bragg-Bentano geometry, provided with an X-ray source with a high stable copper anode and an energy dispersive detector SOL-X has been used. The experimental conditions were: measurement range $2-50^{\circ} 2 \theta$ with time step-scanned of $1 \mathrm{~s}$, fixed-angle divergence slit of $0.02^{\circ} 2 \theta$. The software used was EVA DIFFRACplus. The semi quantitative analysis of the crystalline phases was done by the Chung method $[15,16]$, set by the three most intense $(h k l)$ crystallographic plane directions for the more representative components.

For scanning electron microscopy, a JEOL JSM820 with microanalysis equipped with a secondary electron detector has been used, with the software Oxford ISIS-Link.

\subsubsection{Adsorption behavior of surfactant on the mineral binder}

The adsorption curve was determined by the method described by [51], mixing for $3 \mathrm{~h}$ at $23^{\circ} \mathrm{C}$ and then centrifuged for $10 \mathrm{~min}$ for the extraction of the liquid phase of the suspension. The $w / b$ ratio used was 2.0. The total organic content was determined on a SHIMADZU TOC-VCSH/CSN total organic carbon (TOC) analyzer. The surfactant adsorbed was determined by the difference between the initial amount of polymer and the amount present in the solutions measured by TOC. This method is typically used for measuring the adsorption of admixtures on cement particles $[5,11,51]$. 


\section{Results}

\subsection{Mineral binder analysis by XRD}

The XRD analysis of the unhydrated mineral binder shows a concentration of $59 \%$ of $\mathrm{CaSO}_{4}$ (anhydrite, the main component), a concentration of $32 \%$ of $\mathrm{CaSO}_{4} \cdot 0.5 \mathrm{H}_{2} \mathrm{O}$ (bassanite) and around $9 \%$ of impurities: $2 \%$ of quartz $\left(\mathrm{SiO}_{2}\right)$, and $7 \%$ of phyllosilicates (bulk represented by the $\mathrm{KAl}_{3} \mathrm{Si}_{3} \mathrm{O}_{10}(\mathrm{OH})_{2}$-Muscovite pattern).

The main mineral binder was obtained by the calcination of natural gypsum (with impurities) from temperatures from 300 to $700{ }^{\circ} \mathrm{C}$; this process can generate a resulting product that contains bassanite, anhydrite III (that transforms into bassanite a few hours after cooling), and anhydrite II-s or anhydrite II$\mathrm{u}$, as also reported by other authors $[9,28,59,71]$.

\subsection{Aerogel water absorption}

During samples preparation, the aerogels showed evidence of different water absorption capacities depending on the concentration of the surfactant in the solution. To some extent this can be assessed by analyzing the amount of water needed for series to reach the fixed flowability (measured by the flow table method). For this we consider that the water required can be distributed into two parts: one for the binder and one for the aerogel. Considering for the binder a water/binder ratio of 0.40 , we then calculate the binder to aerogel ratio of the remaining portion of the added water, which is considered to be absorbed into the aerogel particles. To consider that this extra amount of water is absorbed by the aerogel, is supported by the observation that in both series the ratio of extra water to aerogel mass is roughly constant.

In particular, the A series showed a constant $2.9 \mathrm{~g}$ of absorbed water per aerogel gram between $\mathrm{A}(10)$ to $\mathrm{A}(30)$ series, with a $10 \%$ increase of the water needed for the $\mathrm{A}(100)$ composites. The B series showed a constant $3.7 \mathrm{~g}$ of absorbed water per aerogel gram between $\mathrm{B}(10)$ to $\mathrm{B}(30)$ series, with an $8 \%$ increase of the water needed for the $\mathrm{B}(100)$ composites. The increase of the water by the $100 \%$ aerogel addition is probably because of the low volume ratios of the mineral binder, requiring additional water to maintain the flowability, therefore, it is not considered to be absorbed by the aerogel particles. However, between the different composite series, the modified aerogel granules of the B series absorbed $27.6 \%$ more water than the aerogels of the A series.

\subsection{Adsorption behavior of surfactant on the mineral binder}

The adsorption of the surfactant on the mineral binder is shown in Fig. 1. The adsorption is linear and complete up to concentrations of $10 \mathrm{mg}$ of surfactant initial/g of mineral binder. At higher dosages the fraction of polymer adsorbing decreases slightly. The plateau adsorption is at $18 \mathrm{mg}$ of surfactant adsorbed/ $\mathrm{g}$ of mineral binder and in these suspensions is reached for a dosage of about $25 \mathrm{mg} / \mathrm{g}$.

\subsection{Physical and mechanical properties of the composites}

The apparent porosities (\%), water absorption, bulk density, compressive strength and thermal conductivity of the samples are shown in Table 3. The aerogel containing samples with more surfactant showed in general, lower mechanical strength, higher thermal conductivity and higher bulk density than the samples with less surfactant.

In the samples without aerogels, adding the surfactant led to an increase of $19 \%$ of the apparent porosity. In presence of a $10 \mathrm{wt} \%$ (35\% volume) of aerogel in both A and B series, the increase was $38 \%$. However, while further increase in the aerogel addition increased the apparent porosity of the B series, it caused porosity to decrease in the A series.

The compressive strength decreases as the content of aerogel particles increased, as expected. However, the surfactant concentration also modified the

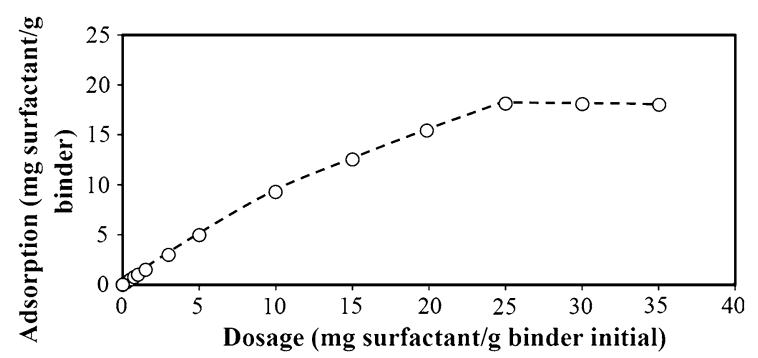

Fig. 1 Adsorption behavior of the surfactant in the mineral binder suspensions 
Table 3 Physical properties of the samples at 7 days. Standard deviation presented in brakets

\begin{tabular}{lllllll}
\hline $\begin{array}{l}\text { Name of } \\
\text { the series }\end{array}$ & $\begin{array}{l}\text { Apparent } \\
\text { porosity }(\%)\end{array}$ & $\begin{array}{l}\text { Water absorption } \\
\left(\mathrm{m}^{2} \mathrm{~min}^{0.5}\right)\end{array}$ & $\begin{array}{l}\text { Bulk density } \\
\left(\mathrm{g} \mathrm{cm}^{-3}\right)\end{array}$ & $\begin{array}{l}\text { Compressive } \\
\text { strength }(\mathrm{MPa})\end{array}$ & $\begin{array}{l}\text { Thermal conductivity } \\
(\mathrm{W} / \mathrm{m} \times \mathrm{K})\end{array}$ & $\begin{array}{l}\text { Aerogel } \\
\text { Volume }(\%)\end{array}$ \\
\hline $\begin{array}{c}\text { Reference } \\
\text { gypsum }\end{array}$ & $21(0.3)$ & $0.5(0.027)$ & $1.38(0.006)$ & $19.3(0.77)$ & $0.282 \pm 0.014$ & - \\
$\mathrm{A}(0)$ & $25(0.2)$ & $0.9(0.022)$ & $1.36(0.01)$ & $17.2(0.19)$ & $0.283 \pm 0.014$ & - \\
$\mathrm{A}(10)$ & $29(0.7)$ & $1.8(0.079)$ & $0.68(0.006)$ & $0.82(0.11)$ & $0.096 \pm 0.005$ & 34.5 \\
$\mathrm{~A}(20)$ & $28(0.3)$ & $2.0(0.099)$ & $0.47(0.003)$ & $0.13(0.01)$ & $0.059 \pm 0.003$ & 44.2 \\
$\mathrm{~A}(30)$ & $26(0.6)$ & $2.1(0.059)$ & $0.37(0.03)$ & $0.06(0.004)$ & $0.059 \pm 0.003$ & 47.9 \\
$\mathrm{~A}(100)$ & $19(1.8)$ & $1.6(0.064)$ & $0.20(0.01)$ & $0.01(0.002)$ & $0.028 \pm 0.001$ & 57.1 \\
$\mathrm{~B}(0)$ & $25(0.2)$ & $0.7(0.026)$ & $1.30(0.016)$ & $12.6(0.35)$ & $0.282 \pm 0.014$ & - \\
$\mathrm{B}(10)$ & $29(0.4)$ & $1.5(0.083)$ & $0.73(0.01)$ & $0.60(0.01)$ & $0.074 \pm 0.004$ & 35.8 \\
$\mathrm{~B}(20)$ & $34(0.6)$ & $2.7(0.061)$ & $0.48(0.01)$ & $0.11(0.04)$ & $0.072 \pm 0.004$ & 43.4 \\
$\mathrm{~B}(30)$ & $35(0.2)$ & $2.9(0.082)$ & $0.39(0.02)$ & $0.05(0.003)$ & $0.065 \pm 0.003$ & 49.5 \\
$\mathrm{~B}(100)$ & $36(4.0)$ & $2.9(0.086)$ & $0.22(0.004)$ & $<0.01(0.001)$ & $0.034 \pm 0.002$ & 59.2 \\
\hline
\end{tabular}

No standard deviation for thermal conductivity are given because only single measurements were performed, each however, giving the average of two samples, as explained in the methods section

properties of the composite materials. The $\mathrm{A}(0)$ and $\mathrm{B}(0)$ series, compared to the reference gypsum, showed 10.9 and $34.7 \%$ lower compressive strength respectively. The $\mathrm{A}(10)$ shows $36.7 \%$ higher compressive strength than the $\mathrm{B}(10)$, however at the highest aerogel concentration, the compressive strength of the A and B series are almost the same.

As shown in Table 3, the reference gypsum (without surfactant) and $\mathrm{A}(0)$ and $\mathrm{B}(0)$ samples presented roughly the same thermal conductivity, showing no significant effect related to different surfactant quantities. However, this situation changes in presence of aerogel particles, where indeed, not only the aerogel addition decrease the thermal conductivity, but also the effect is different between series A and B due to the amount of surfactant.

\subsection{Microstructure study of the composites by SEM}

The SEM images show the most representative microstructure of each sample (Figs. 2, 3). The reference gypsum presented irregular pore morphologies (Fig. 2a). The $\mathrm{A}(0)$ and $\mathrm{B}(0)$ samples presented similar irregular pore morphologies (Fig. 2b, c respectively) as the reference gypsum, but also presented some additional pores with spherical morphology, not detected in the reference sample, generated by the surfactant. The $\mathrm{B}(0)$ sample presented a higher concentration of the spherical pores compared the $\mathrm{A}(0)$ sample, consistent to the increase of surfactant dosage.

Different crystal morphology, growth and microstructure of gypsum are observed within samples depending on their aerogel contents (Fig. 3). The reference gypsum, the $\mathrm{A}(0)$ and the $\mathrm{B}(0)$ samples present crystals with a tabular morphology sized from $1 \times 1 \times 5$ to $2 \times 2 \times 10 \mu \mathrm{m}$, however, the samples $\mathrm{A}(0)$ and $\mathrm{B}(0)$ present also some smaller crystals, with crystal sizes up to $0.5 \times 0.5 \times 1 \mu \mathrm{m}$ generated by the surfactant dosage increase (Fig. 3a).

The SEM images show crystallization of gypsum at the aerogel-gypsum interface in all cases. The crystal growth behavior and morphology changed when the aerogel particles were present, especially in the highest aerogel addition samples (B(100), Fig. 3c), leading to tabular, planar and needle like crystals with sizes up to $0.5 \times 0.5 \times 15 \mu \mathrm{m}$. No visible changes regarding the crystal morphologies were detected between $\mathrm{A}$ and $\mathrm{B}$ series containing aerogel particles.

\subsection{Anhydrite hydration by XRD}

The X-Ray analysis results shows the different mineralogical phases obtained after hydration for both the low and high concentration of surfactant as well as for the different aerogel contents.

Table 4 shows the evolution of the different mineralogical phases during the hydration of the 



Fig. 2 SEM of the reference gypsum $-\mathbf{a}(\times 100), \mathrm{A}(0)-\mathbf{b}(\times 100)$ and $\mathrm{B}(0)-\mathbf{c}(\times 100)$
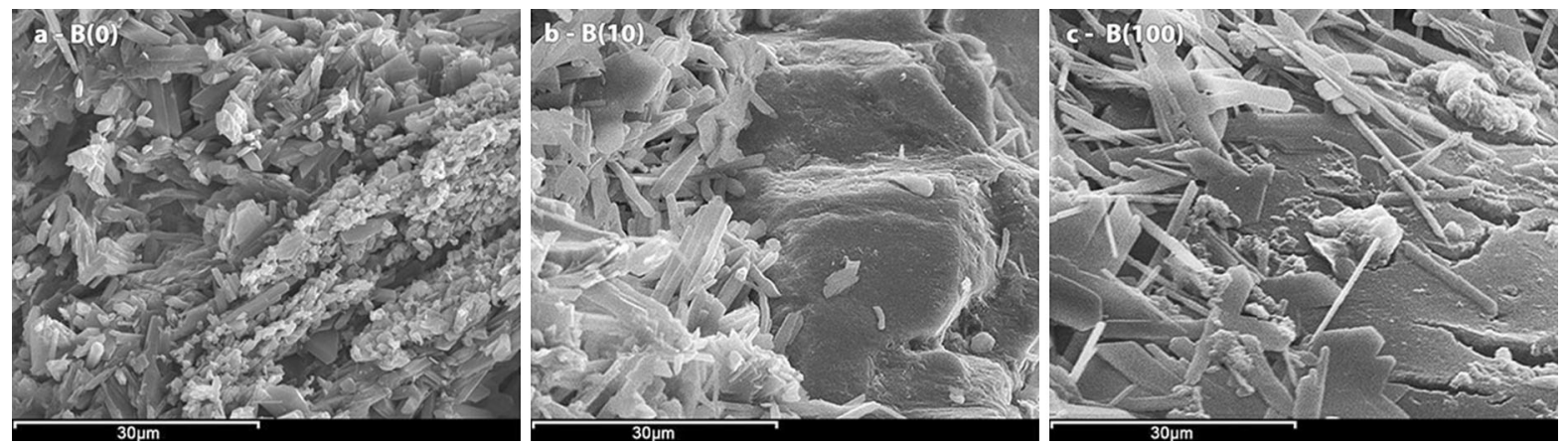

Fig. 3 SEM of the most representative samples: $B(0)-\mathbf{a}(\times 2000), B(10)-\mathbf{b}(\times 2000)$ and $B(100)-\mathbf{c}(\times 2000)$

Table 4 Semiquantification $(\%)$ and analysis of the degree of hydration (DOH) of the calcium sulfates by XRD at 7 days

\begin{tabular}{llllllllllll}
\hline Phase & $\begin{array}{l}\text { Reference } \\
\text { gypsum }\end{array}$ & $\mathrm{A}(0)$ & $\mathrm{A}(10)$ & $\mathrm{A}(20)$ & $\mathrm{A}(30)$ & $\mathrm{A}(100)$ & $\mathrm{B}(0)$ & $\mathrm{B}(10)$ & $\mathrm{B}(20)$ & $\mathrm{B}(30)$ & $\mathrm{B}(100)$ \\
\hline Gypsum (\%) & 90 & 84 & 86 & 89 & 84 & 74 & 83 & 94 & 92 & 88 & 85 \\
Bassanite (\%) & 3 & 1 & 1 & 2 & 3 & 7 & 1 & 2 & 3 & 5 & 8 \\
(DOH) & 0.91 & 0.97 & 0.97 & 0.94 & 0.91 & 0.80 & 0.97 & 0.94 & 0.91 & 0.86 & 0.77 \\
Anhydrite (\%) & 7 & 15 & 13 & 9 & 14 & 19 & 16 & 4 & 5 & 7 & 7 \\
(DOH) & 0.89 & 0.77 & 0.80 & 0.86 & 0.78 & 0.71 & 0.75 & 0.94 & 0.92 & 0.89 & 0.89 \\
\hline
\end{tabular}

calcium sulfates within the samples from XRD analysis, without impurities. Moreover, there is a certain heterogeneity among the samples, primarily concerning the phyllosilicates.

After 7 days, the gypsum with a 0.45 water/binder (w/b) ratio, presented an almost complete anhydrite/ bassanite hydration, with a remaining unhydrated anhydrite and bassanite of 7 and $3 \%$ respectively.

The addition of surfactant reduces by around $6 \%$ the hydration of the calcium sulfates compared to the reference gypsum. In presence of aerogel granules, the formation of gypsum is also reduced as the addition of aerogel content is increased. However the A series presented higher quantities of anhydrite and hemihydrate compared to the B series.

\section{Discussion}

It has been shown that it is possible to compatibilize hydrophobic silica aerogels particles with water-based mineral binders to form highly insulating composites 
by using a surfactant to modify the aerogel's interaction with water. In view of understanding the factors that control the performance of the resulting composites, a systematic study was performed using two different dosages of surfactant and several different aerogel contents.

\subsection{Water accessible porosity}

The surfactant modifies the aerogel surface generating a hydrophilic coating around the hydrophobic core. Depending on the amount of surfactant added, the amount of water that penetrates into the aerogel granules varies; however, there is a minimum surfactant dosage needed to change the aerogel's hydrophobic behavior and to allow the formation of a slurry. For the surfactant used in this study, this amount has been found at a $0.1 \% \mathrm{wt}$. addition with respect to water. To notice that the interaction of the aerogel particles with water changes suddenly at the mentioned surfactant amount, thus lowering the surfactant addition does not provide the compatibility needed to form slurries. This results into a fixed amount of water and a fixed amount of surfactant related to the aerogel addition, to which the water needed by the mineral binder to form a slurry must be added. The relationship between the surfactant and the water suggests that the surface tension of the solution should be decreased enough to be able to form the slurries.

An interesting result is that although more water is needed as the aerogel content is increased, this amount is roughly constant with respect to the mass of aerogel particles and this regardless of the surfactant dosage. This suggests that a constant amount of water is absorbed in the aerogels. Further increase of the amount of surfactant will increase the aerogel's water absorption (up to 3.7 grams of water per aerogel gram, for a $5 \%$ wt. surfactant addition in respect to water).

\subsection{Engineering properties of composites}

\subsubsection{Mechanical behavior of composites}

The final distribution by volume of the components within the mixtures in the fresh state, set (both dry and water saturated) is presented in Fig. 8. These values are calculated using the skeletal density of the aerogel particles, the particle density, the water absorbed by the aerogel particles and the surfactant adsorbed by the mineral binder. The gypsum formation of each sample, in the dry state, is calculated by the DOH measured by XRD. They provide a basis for more detailed consideration of the water distribution in these samples.

In particular, they highlight the fact that during sample preparation, the aerogel particles are capable of absorbing not only a very high amount of water, but also of surfactant. This value is obtained by considering that in the sample preparation the surfactant solution first reaches an equilibrium with the mineral binder, so the surfactant concentration decreases in relation to the data presented in Fig. 1. Using the reduced concentration and the amount of liquid invading the aerogel we can calculate the amount of surfactant that can be considered to have been absorbed into this material. This provides a lower bound for the amount of surfactant absorbed in the aerogel, assuming that the surfactant does not get displaced from the mineral binder to the aerogel owing to a higher adsorption energy on the latter.

Moreover, as observed in Fig. 4, the addition of aerogel and surfactant together increase the air content within the mixtures, by a constant of $0.7 \mathrm{~m}^{3}$ and $0.6 \mathrm{~m}^{3}$ of air per $\mathrm{m}^{3}$ of aerogel for the low and high surfactant content respectively (Fig. 5).This unexpected behavior generates an air volume of around $40 \%$, which decreases the volume fraction of aerogel and the gypsum, compromising both thermal conductivity and strength.

Also, as shown before in Fig. 2, the surfactant causes an increase in the air content in absence of aerogel particles, forming air bubbles. This is explained by the fact that the surfactant molecules tend to minimize unfavorable interactions between the liquid phase and the surfactant lipophilic tail, aligning to form a monolayer at the interface between the liquid phase and the compressed air. The air bubbles are stabilized in the slurry by the electrostatic and steric repulsions of the surfactants; the interfacial properties at the air bubble surfaces are determined by its physical and chemical properties given by the nature and concentration of the surfactants [19]. This surfactant foaming ability has been well established and studied by other authors [19, 46, 49, 70, 73]. Nevertheless, in presence of aerogel particles, no stabilized air bubbles within the composites were detected; although, an important amount of air entrained is measured. 


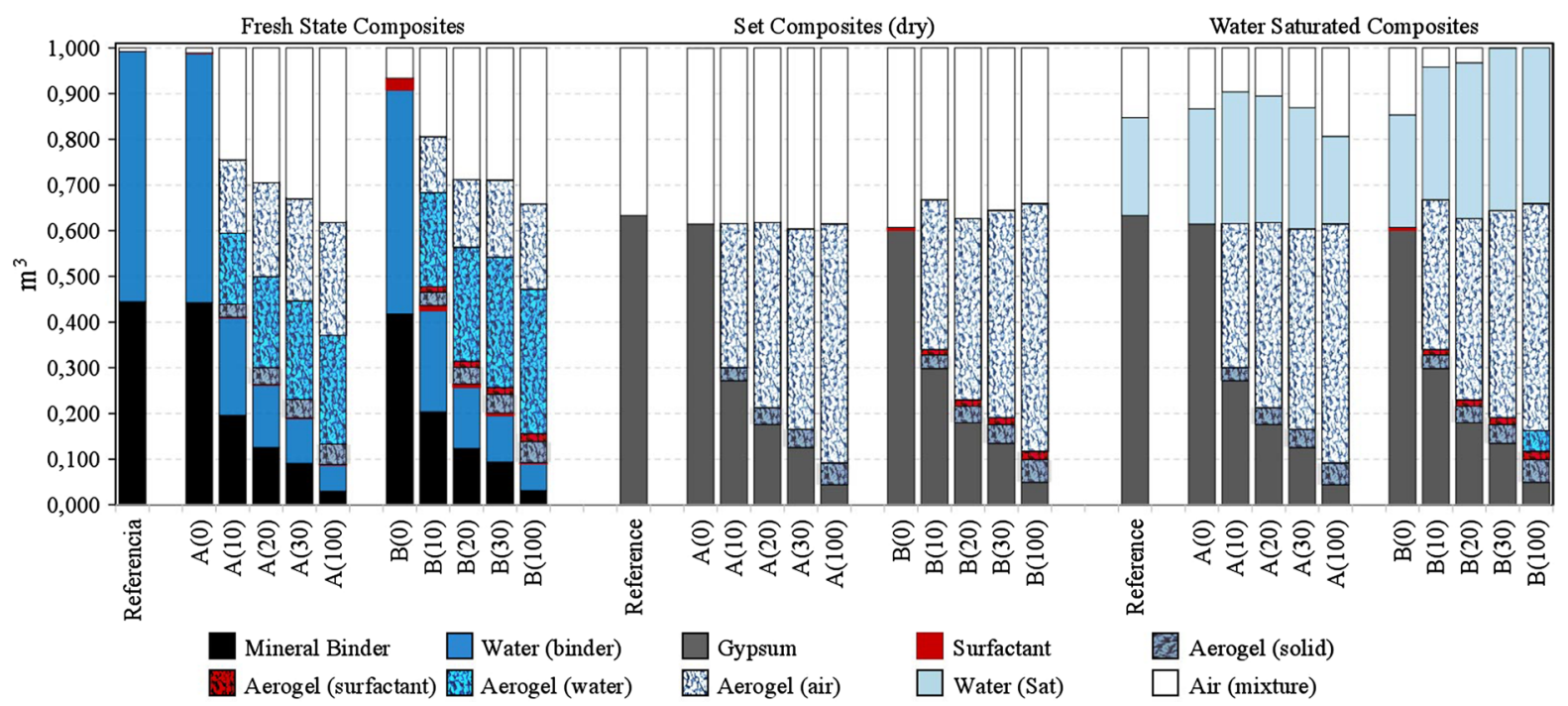

Fig. 4 Components of the composites by volume $\left(\mathrm{m}^{3}\right)$ in fresh, set and water saturated state

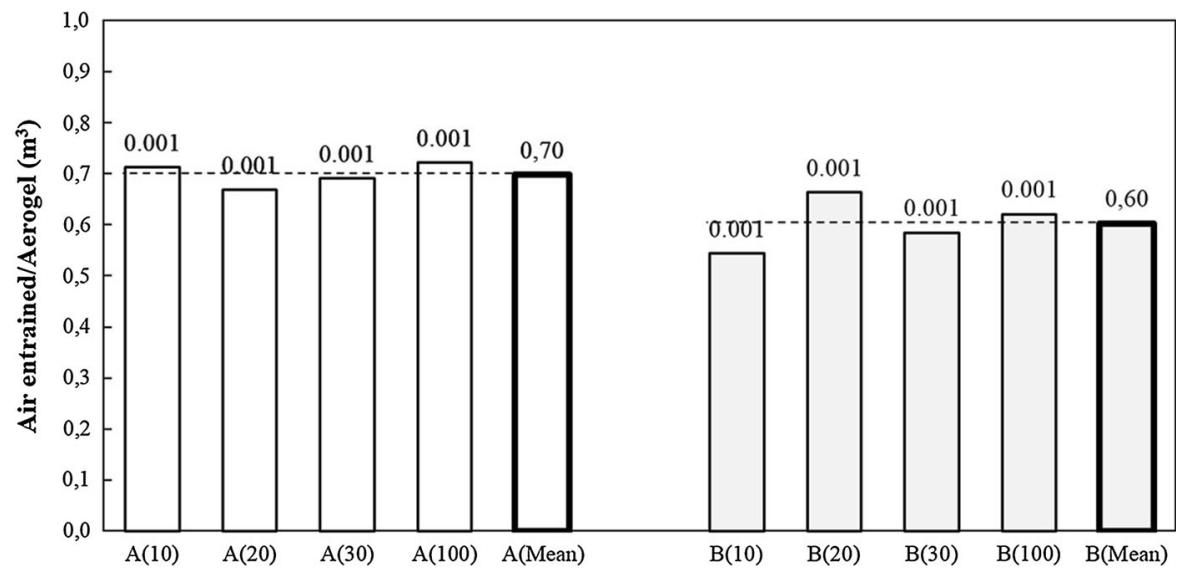

Fig. 5 Volume of air entrained into the mixture by aerogel unit volume $\left(\mathrm{m}^{3}\right)$

The inclusion of aerogel increases the total porosity as expected (Fig. 6). However, as observed in Fig. 4, only part of the total porosity can be assigned to the aerogel structure, while another important part is located within the gypsum matrix. Interestingly, the water accessible porosity of these composites is lower than the volume of air entrained within the gypsum matrix, which suggests that in the set composites, water does not partially invade the aerogel, unlike as in the fresh state. Nevertheless, the water accessible porosity between the A and B series (with different surfactant ratio) is quite different (Fig. 6). The highest surfactant ratio leads to an increased water uptake (B

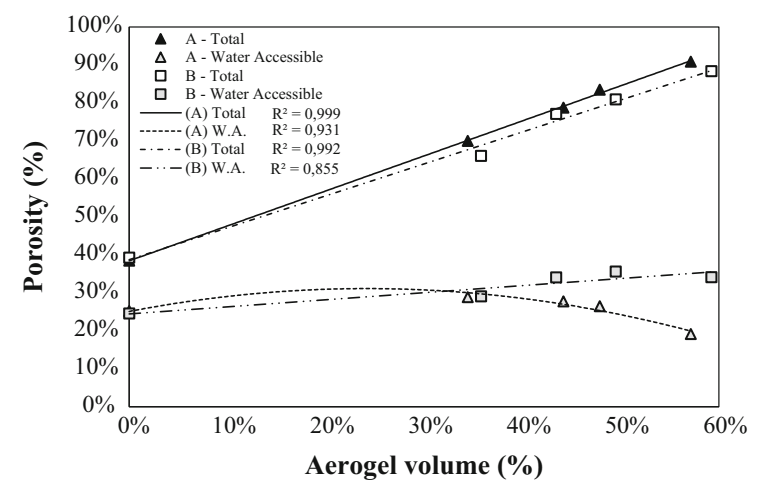

Fig. 6 Total and Water accessible porosities (\%) per aerogel volume $(\%)$ of samples 
series), as can be expected for the modified aerogel's hydrophobic to hydrophilic behavior. However, the samples with the lowest surfactant ratio (A series) show a decreasing water accessible porosity with increasing aerogel content. Here the primary hydrophobic nature of the aerogels themselves and the lower surfactant dosage can be argued to account for this behavior.

Therefore, depending on the surfactant and aerogel concentration, it can be achieved different water absorption capacities within the composites.

The crucial and most important side effect of the air entrained by the aerogel granules is observed within the gypsum in the composites, decreasing the bulk density of the matrix from $1354 \mathrm{~kg} / \mathrm{m}^{3}$ down to $233 \mathrm{~kg} / \mathrm{m}^{3}$ as the aerogel content is increased (Fig. 7).

The schematic illustrations in Fig. 7 explain the changes in mechanical properties of the composites. As the aerogel content is increased, more water is needed in the mix and more air is entrained, so that the binder density decreases (shown by using lighter color). Moreover, the cross-section of the matrix, which bears the load, decreases. Both changes negatively affect the strength. Very interestingly they also combine to give a direct dependence of compressive strength on the volume fraction of gypsum in the mix as can be observed in Fig. 8 .
A possible second order effect could be an impact of the admixture on the hydration kinetics of the anhydrite binder, either in terms of dissolution, nucleation or growth. This would however mainly affect the amount of gypsum formed and therefore strength. It would therefore be a kinetic factor hidden behind the relation revealed in Fig. 8. Apart from this, a modification of gypsum morphology may also modify intercrystalline bonding (Fig. 3c), as already

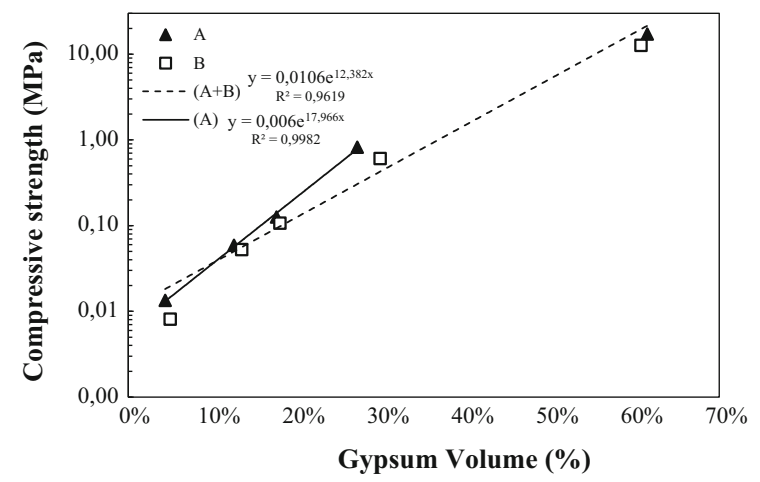

Fig. 8 Compressive strength versus volume fraction of gypsum. The continuous line is an exponential fit for the $\mathrm{A}(10)$ to $\mathrm{A}(100)$ samples. The discontinuous line is an exponential fit for all the samples. Both are consistent with the volume controlling the strength of the composite

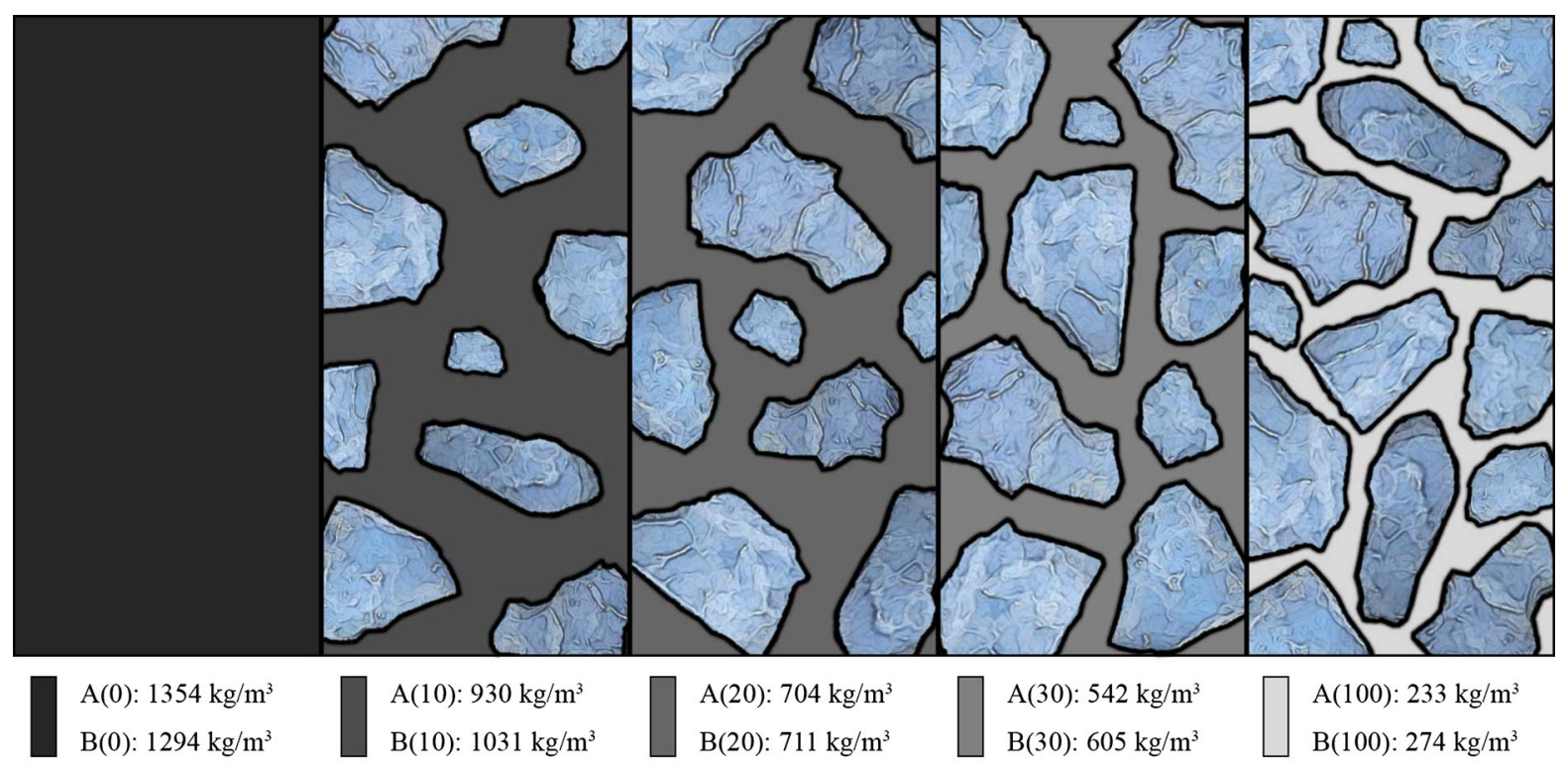

Fig. 7 Density of the gypsum matrix of the composites. The fact that the matrix density increases as aerogel particles are added, owing to the increased amount of entrained air, represented by the lightening shade of the continuous phase 
proposed elsewhere [62]. However, the impact of hydrate morphology on strength is beyond the scope of this paper, and while probably of second order important, it is nevertheless something that we hope to investigate in the future.

\subsubsection{Thermal conductivity of composites}

The thermal conductivity of our composites depend on the volume fractions and thermal conductivities of gypsum, aerogel and air. In what follows we propose a way to estimate this on the basis of the proportions of these three phases. In particular, it is proposed to handle this in a two stage process. We emphasize here that the assumption of a fixed $w / b$ in the matrix only affects the composition listed for the fresh state in Fig. 4, but not the dry state ones, which are those used in the model.

First we calculate the thermal conductivity of the matrix, considered as a mixture of air (phase A) and gypsum (phase B). In a second step, calculate the conductivity of the composite, considered as mixture of the aerogel (phase $A^{*}$ ) and of the matrix (Phase $B^{*}$ ) determined in the first step. In both steps we use the same mixing rules to calculate the composite conductivity based on [33]. This relies on calculating upper $\left(k_{\mathrm{U}}\right)$ and lower $\left(k_{\mathrm{L}}\right)$ bounds of the thermal conductivity using the following equations:

Model A(Upper bound): $k_{\mathrm{U}}$

$$
=k_{\mathrm{B}}+\emptyset_{\mathrm{A}} /\left(\frac{1}{k_{\mathrm{A}}-k_{\mathrm{B}}}+\frac{1-\emptyset_{\mathrm{A}}}{3 k_{\mathrm{B}}}\right)
$$

Model $\mathrm{B}($ Lower bound $): k_{\mathrm{L}}$

$$
=k_{\mathrm{A}}+\left(1-\emptyset_{\mathrm{A}}\right) /\left(\frac{1}{k_{\mathrm{B}}-k_{\mathrm{A}}}+\frac{\emptyset_{\mathrm{A}}}{3 k_{\mathrm{A}}}\right)
$$

$\emptyset_{\mathrm{A}}=$ Phase A volume fraction, $k_{\mathrm{A}}=$ Phase A $k$, $k_{\mathrm{B}}=$ Phase $\mathrm{B} k$.

The authors of this model initially proposed to use the arithmetic mean of the $k_{\mathrm{U}}$ and $k_{\mathrm{L}}$ to evaluate the thermal conductivity of the composite material. However, we found that for our composites, the geometric mean provides results in much better agreement with our experimental data. Therefore in both steps we calculate the composite thermal conductivities as:

Model C: $k=\sqrt{k_{\mathrm{U}} k_{\mathrm{L}}}$

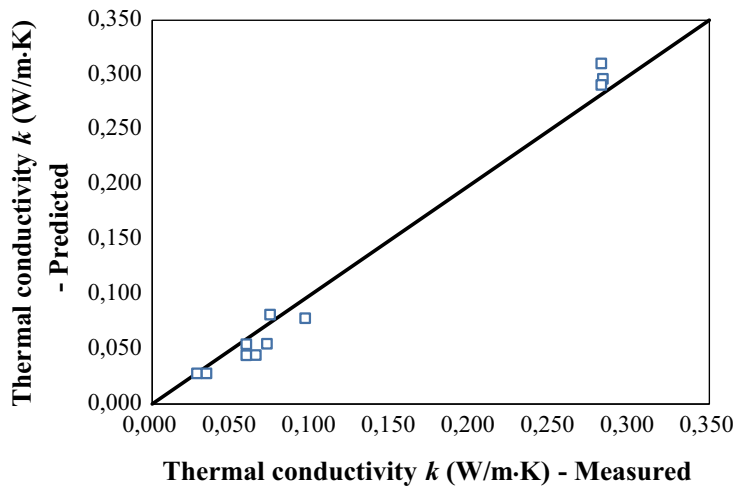

Fig. 9 Plot of thermal conductivity showing experimental values versus those predicted with the model based on Eqs. (1)-(3). The continuous line represents the data obtained from the proposed model according to the respective volume proportions in our study

Numerical applications were done using the following thermal conductivity values for the phases: $k_{\text {Aero- }}$ gel $=0.013 \mathrm{~W} / \mathrm{m} \times \mathrm{K}, k_{\text {Binder }}=1.25 \mathrm{~W} / \mathrm{m} \times \mathrm{K}$ (Gypsum solid phase) from [33] and $k_{\text {Air }}=0.026$ $\mathrm{W} / \mathrm{m} \times \mathrm{K}$, while the volume fractions of the phases come from our measurements reported in Fig. 4.

The model predicts extremely well all our measurements without the inclusion of any fitting parameter, as shown in Fig. 9. We can therefore conclude that this model can reliably be used to estimate thermal conductivities having compositions in the range of those reported in this work. It does however have some limitations, in particular the link between scales. Indeed, including a phase in one or another level of the homogenization procedure does not lead to the same result. The definition of the phases to be included at each stage of the homogenization is therefore crucial. In our samples, taking air and gypsum as first level, leads to good results. However, this should not obscure the risk misinterpretations that may result in applying the same model to other systems.

\subsection{Towards an optimization of aerogel composites}

In practical terms, the optimization of these composites will involve a compromise between reducing thermal conductivity and losing strength when the aerogel content is increased. From this perspective, it is useful to plot compressive strength versus thermal conductivity as in 
Fig. 10. This reveals a relation between both properties, highlighting the difficulty of substantially increasing strength at a defined thermal conductivity.

In practical terms significant strength improvements, may not be easily noticeable in Fig. 10 because of the logarithmic scale. For this reason, we included the two discontinuous lines representing respectively an improvement and a worsening of strength by a factor 5. Achieving such a strength increase without changing the thermal conductivity would already be very interesting in practice. Such effects are within the "scatter" of the data reported in Fig. 10, suggesting that second order effects can play an important effect in this optimization process.

These changes may relate to modifications of the microstructure. Although of second order with respect to the main factor of gypsum content, they probably offer useful avenues to exploit for optimization. For example only may consider trying to eliminate the air entrained during the preparation of these materials as it does not contribute to strength and has a higher thermal conductivity that the aerogel granules (entrained air is about $40 \%$ by volume as shown in Fig. 4). This would probably worsen the fluidity of the paste, which would then possibly have to be adjusted by the inclusion of chemical admixtures such as superplasticizers [23, 29].

This optimization of component proportions would include two main options. The first is to replace the volume of entrained air with aerogel to reduce the overall thermal conductivity. This would not change



Fig. 10 Experimental values of thermal conductivity versus compressive strength. The continuous line corresponds to a power law that fits all the data points presented in the graph. The dotted lines represent an increase and decrease of the compressive strength by a Factor of 5 the volume fraction of gypsum and should consequently leave the strength unchanged in accordance with Fig. 8. The second option consists in increasing strength without changing the thermal conductivity. For this, the right proportion of gypsum and aerogel must be determined for replacing the air. Changes in strength would be best estimated using the exponential fit of the $A(10)$ to $A(100)$ samples presented as the continuous line in Fig. 8.

The thermal conductivity can be estimated using our model. Because of the previously mentioned issue of homogenization, the same two step procedure would be used. Here however, in the first step the air volume would be replaced by a mixture of gypsum and inclusions having the same thermal conductivity as the aerogel. Following this procedure, we find that the changes proposed would provide substantial improvements as can be observed in Fig. 11.

Replacing the volume of entrained air by aerogel would improve the overall thermal insulation of the composites, as shown in Fig. 11. Fixing the volume of gypsum, and thereby the strength would decrease the thermal conductivity of the samples by about $20 \%$, providing a very interesting ultralow thermal conductivity of $23 \mathrm{~mW} / \mathrm{m} \times \mathrm{K}$ for our $\mathrm{A}^{\prime}(100)$ and $63 \mathrm{~mW} / \mathrm{m}$ $\times \mathrm{K}$ for $\mathrm{A}^{\prime}(10)$. Moreover, modifying the volume of gypsum and fixing the thermal conductivity value would improve the strength significantly: $82.5 \%$ $(0.024 \mathrm{MPa})$ and $227.4 \%(2.57 \mathrm{MPa})$ respectively for $A^{\prime \prime}(100)$ and $A^{\prime \prime}(10)$. Figure 11 also shows what would happen if all the aerogel were replaced by air,

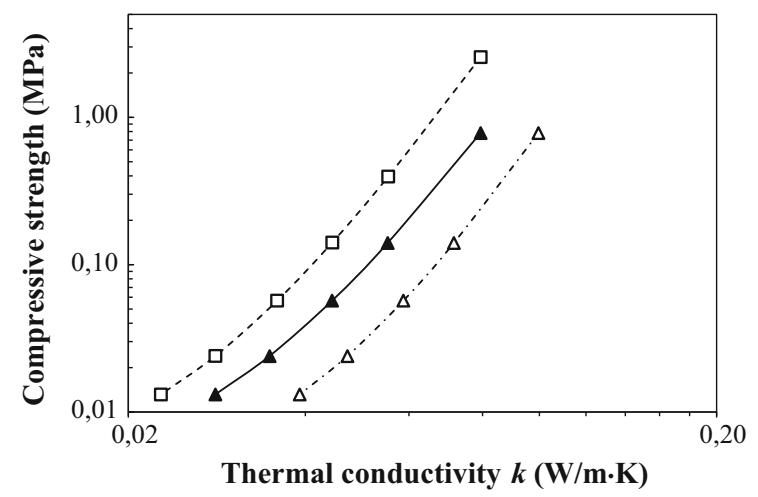

Fig. 11 Predicted values of thermal conductivity versus compressive strength. The continuous line corresponds to the data calculated with a $40 \%$ of air by volume (A). The dashed line corresponds to the replacement of the mentioned air by aerogel $\left(\mathrm{A}^{\prime}\right)$. The dash-dotted line corresponds to a replacement of the aerogel by air $\left(\mathrm{A}^{\prime \prime}\right)$ 
without changing the content of gypsum. The thermal conductivity would increase by $57 \%$ for $\mathrm{A}^{\prime \prime}(10)$ and by $72 \%$ for $A^{\prime \prime}(100)$ compared to the corresponding samples $A^{\prime}(10)$ and $A^{\prime}(100)$ respectively. This clearly illustrated the benefit of using aerogel to enhance the thermal insulation capacity of these composites.

Finally, we can also mention that changes in morphologies of hydrates may be beneficial, for example by enhancing the intercrystalline bonding in the matrix and/ or the bonding between the granules and the matrix. Our results show that such changes take place, but a detailed discussion of how to exploit this in an optimization procedure is beyond the scope of this article.

\section{Conclusions}

Ultra lightweight (around $200 \mathrm{~kg} / \mathrm{m}^{3}$ ) and high thermal insulating (around $30 \mathrm{~mW} / \mathrm{m} \times \mathrm{K}$ ) gypsum composites can be achieved by the addition of a $100 \%$ by wt. of nanoporous hydrophobic aerogel particles through a hydrophilization process in order to stabilize the composite slurries, as showed in the present study. However, an around $40 \%$ of air volume content entrained can be found within the mixtures, lowering the mechanical properties more than expected. Moreover, by changing the hydrophobic behavior of the aerogels with surfactants (at least a $0.1 \%$ addition to the mixture's solution) very high/ binder ratios are required, possibly affecting the hydration of the anhydrite binder.

This type of composite can be suitable for exterior renderings on buildings. If used as a single layer, the optimum aerogel particles might be considered at a 10 by wt $\%$ (with a $k$ between 74 and $96 \mathrm{~mW} / \mathrm{m} \times \mathrm{K}$ ). The composites with $100 \%$ by wt. aerogel addition could be used as insulating layers, once future material optimization is done (to reach at least $0.08 \mathrm{MPa}$ ), but requiring a protective exterior layer, which can be the anhydrite-based mortar presented in this experiment. However, the improved insulating layer should be reinforced with a mesh, as other products in the market. Nevertheless, the experiments and analysis presented in this paper, set as a basis for future material development, requiring additional experiments regarding the application of these composites as an exterior thermal insulating renderings, like weathering chamber tests and large scale specimens, or energy efficiency analysis. Moreover, additives like superplasticizers to reduce the mixture water content and its effect on the anhydrite will also be studied.

Acknowledgments The authors wish to show their gratitude to the Centre for Research Assistance of Geological Techniques Laboratory of the Complutense University of Madrid, and the Construction Materials Laboratory of the School of Architecture of the Polytechnic University of Madrid for supporting us with the laboratory equipment and facilities. Special thanks to Dr. Marta Palacios from Institute for Building Materials of ETH Zurich for her technical assistance. We want to thank CTH Navarra (Spain) for the anhydrite supply, and BASF (SpainGermany) for the surfactant supply. Also, we want to show our gratitude to Aidico Laboratories (Valencia) for the thermal conductivity measurements.

\section{References}

1. AAC_11.3_RILEM (1992) Determination of the thermal conductivity of oven dry AAC (dynamic method)

2. Abenza-Ruiz B (2009) Aplicación del yeso en exteriores: análisis de dosificaciones en laboratorio y estudio de campo en la ciudad de Cuenca. Paper presented at the Historia de la Construcción, Valencia

3. Achard P, Rigacci A, Echantillac T, Bellet A, Aulagnier M, Daubresse A (2011) Insulating Silica Xerogel plaster. WO 2011083174, 14-Jul-2011

4. Akimov YK (2003) Fields of Application of Aerogels (Review). Instrum Exp Tech 46:287-299

5. Alonso MM, Palacios M, Puertas F (2013) Compatibility between polycarboxylate-based admixtures and blendedcement pastes. Cement Concr Compos 35:151-162. doi:10. 1016/j.cemconcomp.2012.08.020

6. Anhydrite II. http://www.cthnavarra.com/cth/web/cth/webcth. nsf/app/Producto/Yeso/Myrsac802. http://www.cthnavarra.com/ cth/web/cth/webcth.nsf/app/Producto/Yeso/Myrsac802

7. Baetens R, Jelle BP, Gustavsen A (2011) Aerogel insulation for building applications: a state-of-the-art review. Energy Build 43:761-769. doi:10.1016/j.enbuild.2010.12.012

8. Baetens R, Jelle BP, Thue JV, Tenpierik MJ, Grynning S, Uvsløkk S, Gustavsen A (2010) Vacuum insulation panels for building applications: a review and beyond. Energy Build 42:147-172. doi:10.1016/j.enbuild.2009.09.005

9. Ballirano P, Melis E (2009) The thermal behaviour of gamma-CaSO ${ }_{4}$. Phys Chem Miner 36:319-327. doi:10. 1007/s00269-008-0280-0

10. Bauer U, Doshi D (2010) Aerogel compositions and methods of making and using them. WO 2010126792 A1, 04-Nov-2010

11. Bowen P, Houst YF, Palacios M, Puertas F (2009) Adsorption of superplasticizer admixtures on alkali-activated slag pastes. Cem Concr Res 39:670-677

12. Cabot Aerogel. http://www.cabotcorp.com/solutions/applic ations/construction/building-insulation. http://www.cabotc orp.com/solutions/applications/construction/building-insulation

13. Çolak A (2000) Density and strength characteristics of foamed gypsum. Cement Concr Compos 22:193-200. doi:10.1016/S0958-9465(00)00008-1 
14. Chen K (2013) Truss core sandwich panels with compacted aerogel insulation. Master Thesis, MIT

15. Chung F (1974) Quantitative interpretation of X-ray diffraction patterns of mixtures. I. Matrix-flushing method for quantitative multicomponent analysis. J Appl Crystallogr 7:519-525. doi:10.1107/S0021889874010375

16. Chung F (1974) Quantitative interpretation of X-ray diffraction patterns of mixtures. II. Adiabatic principle of X-ray diffraction analysis of mixtures. J Appl Crystallogr 7:526-531. doi:10.1107/S0021889874010387

17. Dalmay P, Smith A, Chotard T, Sahay-Turner P, Gloaguen V, Krausz P (2010) Properties of cellulosic fibre reinforced plaster: influence of hemp or flax fibres on the properties of set gypsum. J Mater Sci 45:793-803. doi:10.1007/s10853009-4002-x

18. Doshi D, Miller T, Chase J, Norwood C (2011) Aerogel composites and methods for making and using them. US Patent 0206471, 25 Aug 2011

19. Du L, Folliard KJ (2005) Mechanisms of air entrainment in concrete. Cem Concr Res 35:1463-1471. doi:10.1016/j. cemconres.2004.07.026

20. EN_1015-18 (2003) European Standard EN 1015-18, Methods of tests for mortar for masonry. Part 18: Determination of water absorption coefficient due to capillary action of hardened mortar

21. EN_13279-2 (2004) European Standard EN 13279-2, Gypsum binders and gypsum plasters-test methods

22. Ferrándiz-Mas V, García-Alcocel E (2013) Durability of expanded polystyrene mortars. Constr Build Mater 46:175-182. doi:10.1016/j.conbuildmat.2013.04.029

23. Flatt RJ, Schober I (2012) Superplasticizers. In: Roussel N (ed) Understanding the rheology of concrete. Woodhead Publishing, Cambridge, pp 144-208

24. Frank D, Zimmermann A, Stuhler H (2000) Composite material containing aerogel, process for manufacturing the same and the use thereof. US 6080475, 27-Jun-2000

25. Gao T, Jelle BP, Gustavsen A, Jacobsen S (2014) Aerogelincorporated concrete: an experimental study. Constr Build Mater 52:130-136. doi:10.1016/j.conbuildmat.2013.10.100

26. García-Santos A (2009) PPF-reinforced, ESP-lightened gypsum plaster. Materiales de Construcción 59:105-124

27. Gibiat V, Lefeuvre O, Woignier T, Pelous J, Phalippou J (1995) Acoustic properties and potential applications of silica aerogels. Proc Fourth Int Symp AEROGELS 186:244-255. doi:10.1016/0022-3093(95)00049-6

28. Gipsdatenbuch (2006). Bundesverband der Gipsindustrie e.V

29. Hampel C, Zimmermann J, Müller M (2013) Optimisation of plasticizers for gypsum applications. Anglais 2:56-61

30. Hanus MJ, Harris AT (2013) Nanotechnology innovations for the construction industry. Prog Mater Sci 58:1056-1102. doi:10.1016/j.pmatsci.2013.04.001

31. Herrero S, Mayor P, Hernández-Olivares F (2013) Influence of proportion and particle size gradation of rubber from endof-life tires on mechanical, thermal and acoustic properties of plaster-rubber mortars. Mater Des 47:633-642. doi:10. 1016/j.matdes.2012.12.063

32. Hong SK, Yoon MY, Hwang HJ (2011) Fabrication of spherical silica aerogel granules from water glass by ambient pressure drying. J Am Ceram Soc 94:3198-3201. doi:10.1111/j.1551-2916.2011.04765.x
33. K-i Horai (1971) Thermal conductivity of rock-forming minerals. J Geophys Res 76:1278-1308. doi:10.1029/ JB076i005p01278

34. Hughes JJ (2012) RILEM TC 203-RHM: repair mortars for historic masonry : e of mortar in masonry: An introduction to requirements for the design of repair mortars. Mater Struct Mater Construct 45:1287-1294. doi:10.1617/s11527012-9847-9

35. Kazuma K (2011) Development of Silica-based Aerogels for Super-insulating Glazing Application. Engineering Degree, Kyoto University

36. Kim S, Seo J, Cha J, Kim S (2013) Chemical retreating for gel-typed aerogel and insulation performance of cement containing aerogel special section on recycling wastes for use as. Construct Mater 40:501-505. doi:10.1016/j. conbuildmat.2012.11.046

37. Koebel M, Rigacci A, Achard P (2012) Aerogel-based thermal superinsulation: an overview. J Sol-Gel Sci Technol 63:315-339

38. Künzel HM, Karagiozis A (2010) 2-Hygrothermal behaviour and simulation in buildings. In: Hall MR (ed) Materials for energy efficiency and thermal comfort in buildings. Woodhead Publishing, Cambridge, pp 54-76. doi:10.1533/ 9781845699277.1.54

39. Kwon Y-G, Choi S-Y, Kang E-S, Baek S-S (2000) Ambient-dried silica aerogel doped with $\mathrm{TiO}_{2}$ powder for thermal insulation. J Mater Sci 35:6075-6079. doi:10.1023/A: 1026775632209

40. La Spina V, Mileto C, Vegas F (2013) The historical renderings of Valencia Spain: an experimental study. J Sci Technol Safeguard Cult Herit Mediterranean Basin 14:S44 S51. doi:10.1016/j.culher.2012.11.011

41. Lazghab M, Saleh K, Guigon P (2008) A new solventless process to hydrophobize silica powders in fluidized beds. AIChE J 54:897-908. doi:10.1002/aic.11436

42. Li G, Yu Y, Zhao Z, Li J, Li C (2003) Properties study of cotton stalk fiber/gypsum composite. Cem Concr Res 33:43-46. doi:10.1016/S0008-8846(02)00915-8

43. Liu H, Sha W, Cooper AT, Fan M (2009) Preparation and characterization of a novel silica aerogel as adsorbent for toxic organic compounds. Interfaces Against Pollution 5th International Conference on Interfaces Against Pollution 2008, Kyoto, Japan, 1-4 June 2008 347:38-44. doi:10.1016/ j.colsurfa.2008.11.033

44. Middendorf B (2002) Physico-mechanical and microstructural characteristics of historic and restoration mortars based on gypsum: current knowledge and perspective. doi:10. 1144/GSL.SP.2002.205.01.13

45. Mielke M, von Dungen K (1997) Moldings containing silica aerogel particles and their preparation. US 5656196

46. Mydin MAO, Wang YC (2012) Mechanical properties of foamed concrete exposed to high temperatures. Constr Build Mater 26:638-654. doi:10.1016/j.conbuildmat.2011. 06.067

47. Neugebauer A, Chen K, Tang A, Allgeier A, Glicksman LR, Gibson LJ (2014) Thermal conductivity and characterization of compacted, granular silica aerogel. Energy Build 79:47-57. doi:10.1016/j.enbuild.2014.04.025

48. Oliver A, Nelia F, García A (2010) Caracterización térmica de placas de yeso con material de cambio de fase incorporado Informes de la Construcción 62 
49. Ouyang X, Guo Y, Qiu X (2008) The feasibility of synthetic surfactant as an air entraining agent for the cement matrix. Constr Build Mater 22:1774-1779. doi:10.1016/j.conbuildmat. 2007.05.002

50. Pacheco-Torgal F (2014) Eco-efficient construction and building materials research under the EU Framework Programme Horizon 2020. Constr Build Mater 51:151-162. doi:10.1016/j.conbuildmat.2013.10.058

51. Palacios M, Flatt RJ, Puertas F, Sanchez-Herencia A (2012) Compatibility between polycarboxylate and viscositymodifying admixtures in cement pastes. Spec Publ. doi:10. $14359 / 51684218$

52. Pigache MR (1986) El enlucido exterior de yeso en las rehabilitaciones de las fachadas de París

53. Pluronic. http://www.basf.com/group/corporate/en/brand/ PLURONIC

54. Rao AV, Pajonk GM, Bhagat SD, Barboux P (2004) Comparative studies on the surface chemical modification of silica aerogels based on various organosilane compounds of the type $\mathrm{RnSiX} 4-\mathrm{n}$. Aerogels 7 Proceedings of the 7th International Symposium on Aerogels 7th International Symposium on Aerogels 350:216-223. doi:10.1016/j. jnoncrysol.2004.06.034

55. Riffat SB, Qiu G (2013) A review of state-of-the-art aerogel applications in buildings. Int J Low-Carbon Technol 8:1-6. doi:10.1093/ijlct/cts001

56. Sanz-Arauz D (2009) Análisis del yeso empleado en revestimientos exteriores mediante técnicas geológicas. $\mathrm{PhD}$ Thesis, UPM

57. Sanz-Arauz D, Villanueva L (2004) Albarracín y el yeso rojo

58. Serhat-Başpınar M, Kahraman E (2011) Modifications in the properties of gypsum construction element via addition of expanded macroporous silica granules. Constr Build Mater 25:3327-3333. doi:10.1016/j.conbuildmat.2011.03. 022

59. Seufert S, Hesse C, Goetz-Neunhoeffer F, Neubauer J (2009) Quantitative determination of anhydrite III from dehydrated gypsum by XRD. Cem Concr Res 39:936-941. doi:10.1016/j.cemconres.2009.06.018

60. Shao L (2010) 25 Materials for energy efficiency and thermal comfort in new buildings. In: Hall MR (ed) Materials for energy efficiency and thermal comfort in buildings. Woodhead Publishing, Cambridge, pp 631-648. doi:10. 1533/9781845699277.3.631

61. Shewale PM, Rao AV, Rao AP (2008) Effect of different trimethyl silylating agents on the hydrophobic and physical properties of silica aerogels. Appl Surf Sci 254:6902-6907. doi:10.1016/j.apsusc.2008.04.109

62. Singh NB, Middendorf B (2007) Calcium sulphate hemihydrate hydration leading to gypsum crystallization. Prog Cryst Growth Charact Mater 53:57-77. doi:10.1016/j. pcrysgrow.2007.01.002

63. Soleimani Dorcheh A, Abbasi MH (2008) Silica aerogel; synthesis, properties and characterization. J Mater Process Technol 199:10-26. doi:10.1016/j.jmatprotec.2007.10.060
64. Stahl T, Brunner S, Zimmermann M, Ghazi Wakili K (2012) Thermo-hygric properties of a newly developed aerogel based insulation rendering for both exterior and interior applications. Energy Build 44:114-117. doi:10.1016/j. enbuild.2011.09.041

65. Taylor T, Counsell J, Gill S (2013) Energy efficiency is more than skin deep: improving construction quality control in new-build housing using thermography. Energy Build 66:222-231. doi:10.1016/j.enbuild.2013.07.051

66. Ülker Z, Sanli D, Erkey C (2014) Chapter Applications of aerogels and their composites in energy-related technologies. In: Anikeev V, Fan M (eds) Supercritical fluid technology for energy and environmental applications. Elsevier, Boston, pp 157-180. doi:10.1016/B978-0-444-62696-7.00008-3

67. Vimmrová A, Keppert M, Svoboda L, Černý R (2011) Lightweight gypsum composites: design strategies for multi-functionality. Cement Concr Compos 33:84-89. doi:10.1016/j.cemconcomp.2010.09.011

68. Wagh PB, Ingale SV (2002) Comparison of some physicochemical properties of hydrophilic and hydrophobic silica aerogels. Ceram Int 28:43-50. doi:10.1016/S0272-8842(01) 00056-6

69. Wang D, Silbaugh T, Pfeffer R, Lin YS (2010) Removal of emulsified oil from water by inverse fluidization of hydrophobic aerogels. Powder Technol 203:298-309. doi:10.1016/j.powtec.2010.05.021

70. Wei S, Yiqiang C, Yunsheng Z, Jones MR (2013) Characterization and simulation of microstructure and thermal properties of foamed concrete. Constr Build Mater 47:1278-1291. doi:10.1016/j.conbuildmat.2013.06.027

71. Wirsching F (2000) Calcium sulfate. In: Ullmann's encyclopedia of industrial chemistry. Wiley-VCH Verlag $\mathrm{GmbH}$ \& Co. KGaA. doi:10.1002/14356007.a04_555

72. Wong JCH, Kaymak H, Brunner S, Koebel MM (2014) Mechanical properties of monolithic silica aerogels made from polyethoxydisiloxanes. Microporous Mesoporous Mater 183:23-29. doi:10.1016/j.micromeso.2013.08.029

73. Yang Q, Zhu P, Wu X, Huang S (2000) Properties of concrete with a new type of saponin air-entraining agent. Cem Concr Res 30:1313-1317. doi:10.1016/S0008-8846(00) 00340-9

74. Yokogawa H, Yokoyama M (1995) Hydrophobic silica aerogels. Proc Fourth Int Symp Aerogels 186:23-29. doi:10. 1016/0022-3093(95)00086-0

75. Yu QL, Brouwers HJH (2012) Development of a selfcompacting gypsum-based lightweight composite. Cement Concr Compos 34:1033-1043. doi:10.1016/j.cemconcomp. 2012.05.004

76. Zhao S, Zhang Z, Sèbe G, Wu R, Rivera Virtudazo RV, Tingaut P, Koebel MM (2015) Multiscale assembly of superinsulating silica aerogels within silylated nanocellulosic scaffolds: improved mechanical properties promoted by nanoscale chemical compatibilization. Adv Funct Mater 25:2326-2334. doi:10.1002/adfm.201404368 